\title{
SIMULATOR VALIDATION RESULTS AND PROPOSED REPORTING FORMAT FROM FLIGHT TESTING A SOFTWARE MODEL OF A COMPLEX, HIGH- PERFORMANCE AIRPLANE
}

\author{
Seamus M. McGovern \\ U.S. DOT National Transportation Systems \\ Center \\ Cambridge, Massachusetts, USA
}

\begin{abstract}
Computer simulations are often used in aviation studies. These simulation tools may require complex, high-fidelity aircraft models. Since many of the flight models used are third-party developed products, independent validation is desired prior to implementation. Due to the variety of processes used by the different industries and organizations that make use of flight models, the proprietary nature of some desired data, the relative availability of data-rich pilot manuals, and their standardized, rigorous nature, formal processes based in experimental and certification flight test are proposed for objectively and consistently validating these models and their associated aircraft types. The results of application of these detailed flight test techniques is then reported using a blade element theory-based flight model with a complex, highperformance aircraft model. Finally, a concise data analysis and reporting format is proposed and demonstrated using this same aircraft model.
\end{abstract}

\section{INTRODUCTION}

When it is desirable to include third-party developed, highfidelity models of aircraft for integration with an aviation software simulation tool, these aircraft models require validation prior to use.

\section{Flight Simulator Models}

There are generally considered to be three ways to mathematically model aircraft in flight [10]. These include the use of basic kinematics, the small perturbation theory model, and the total forces and moments method (including calculations provided by blade element theory). While a completely accurate computation that includes all possible flight regimes is impractical due to the formidable problem of solving the complete Navier-Stokes equations, the difference in accuracy between this exact solution and the center of mass flight path for an aircraft using one of these methods is generally small under the conditions of interest (i.e., laminar flow).

For the simplest simulator, a kinematic model consisting of only kinematic relations can be used [11]. Kinematics describes an object's motion using non-dynamical equations that involve only positions, velocities, and accelerations. Based in physics and devoid of any type of aerodynamic or stability components, this model relies, with few exceptions, purely on the kinematic motion of the aircraft. Benefits include simplified calculations (enabling quicker design and software coding as well as faster calculations), no requirement for aircraft type-specific - and typically proprietary - data (e.g., lift and drag coefficients), and reduced computational workload.

The small perturbation method provides an incremental step in performance. Simplifying the nonlinear aircraft equations of motion results in the formation of the aircraft stability derivatives; these derivatives are an intuitive way of describing aircraft motion around a certain equilibrium point. However, this method is limited by this: as its name implies, the model provides a description of motion, but only around an equilibrium point. For an aircraft in a steep dive or a wide speed range, this method is unable to produce accurate results. This model is valuable and commonly used in aircraft development and test when limited aircraft data is available.

Using the total forces and moments method - the most widely used method in the simulator industry - the complete nonlinear aircraft equations of motion are solved. As with all of these models, the aircraft is assumed to be a rigid body; however, the aircraft now has six degrees of freedom for application of all forces and moments. The forces and moments are found for an entire aircraft using various methods, including table lookup and polynomial representation. Using 
common integration algorithms, the aircraft's position is calculated as a result of these forces and moments at each time step. Although these formulations are quite detailed, there are still errors that arise from their use. If tabular data is used, it will not be smooth, but piecewise linear; this can prove to be an inadequate representation of smooth real-world data. A table also has a beginning and an end, past which there is no aircraft data (some simulators hold the first and last values constant beyond these limits, while others extrapolate out). A lesserused total forces and moments method employs blade element theory, first derived for use with the analysis of helicopter rotors. In this method, the wing is split up into thin strips essentially two-dimensional, infinite-span airfoils. Since the aerodynamic properties of two-dimensional airfoils are readily calculated, the sum of these over the entire wing will produce the net forces and moments on the wing and subsequently on the entire aircraft.

\section{Validation Options}

A wide variety of tests exist for providing simulator validation [9]; some evaluate the software code itself, while others evaluate the airframe or the pilot. These include: generalized software verification and validation/quality assurance, observation/inspection of aircraft simulator actions and performance, regulatory agency simulation qualification, experimental flight testing, maintenance flight testing, pilot examinations, and pilot operating handbook (POH) comparisons. (Other tests and test formats not discussed here include: developmental test and evaluation; operational test and evaluation; and research, development, test, and evaluation structures.)

Generalized software verification and validation may include technical reviews (inspections, audits, group meetings, etc.), software testing (i.e., exercising a product to verify results), and requirements verification (i.e., ensuring that a product and its testing addresses all requirements). A component of these is quality assurance testing, which uses the techniques of observation (of a behavior) and exercise (executing the software in a manner consistent with its intended use) to confirm the existence or function of a requirement.

Observation and inspection are of value when, for example, the only way it may be feasible to test a model due to its design (e.g., a kinematics-based model with no ability for control and test by an actual pilot manipulating flight controls, as may be the case with a model used for efficiency/queuing studies) may be through a non-functional test. In this case, the model may be exercised through the use of pre-determined instructions, and then the model's actions are observed to ensure expected characteristics and performance.

The military services have their own criteria for validating their various simulation devices. These requirements are often bound by contractual agreements between the service and the vendor; however, these agreements often default to Federal Aviation Administration (FAA) norms. Major differences may exist between simulator specifications that cite, for example,
FAA transport category aircraft simulator criteria as the basis for satisfactory flight characteristics, rather than requirements tailored to military pilot training as advocated by Government technical personnel [7]. These differences can include the methods for validating the simulator flight characteristics and in the approach to test and evaluation of the devices.

Various regulatory agencies are involved in determination of simulation qualification standards [17]. These agencies have well-established standards for certifying various types of flight simulation devices. Some of these agencies include the FAA in the U.S., the European Joint Airworthiness Authority in the European Union, the Civil Aviation Authority (CAA) in the United Kingdom, the CAA in Australia, Transport Canada in Canada, the International Civil Aviation Organization (ICAO), and the Royal Aeronautical Society. As is typical for the FAA, validation flight test data (electronically recorded in an airplane using a calibrated data acquisition system) are used to establish a reference set of relevant parameters to which like simulator parameters can be compared. This data is provided by the simulator manufacturer to the FAA in a time-history format (a presentation of the change of a variable with respect to time; it is usually in the form of a continuous data plot over the time period of interest). This allows for the FAA Simulator Evaluation Specialist to fly the profiles described in AC 12040B [2], record the desired data, compare the collected parameter and time data with the manufacturer-provided time history of the actual aircraft performing the same flight profile, and then perform a validation using the AC 120-40B-specified tolerances.

Experimental (also known as engineering, developmental, or certification) test flights are conducted to determine or demonstrate critical operating characteristics of an aircraft. A typical flight test program may consist of: high-speed taxi, first flight, envelope expansion, high angles of attack (stall and turning flight), maximum rate of climb/excess power, maximum glide endurance/thrust required, static stability handling qualities (longitudinal static stability without trim, and longitudinal static stability with trim), dynamic stability handling qualities (longitudinal dynamic stability for phugoid and for short-period response), lateral and directional dynamic stability cross coupling (directional divergence, spiral divergence, and Dutch roll dynamic effects), control (longitudinal, lateral, and directional), and engine-out performance and asymmetric qualities.

Maintenance flight testing (also known as production, acceptance, or functional checks) is performed for new aircraft acceptance, post-maintenance performance confirmation, or for in-flight malfunction diagnosis. Maintenance test flights are designed to determine whether the airframe, power plant, accessories, and other items of equipment are functioning in accordance with predetermined standards while subjected to the intended operating environment. Military maintenance test flights are performed after all 100-hour inspections and after replacement or removal and reinstallation of any flight controls or surfaces, engines, engine controls, or gearboxes [15]. They 
may also be performed in some form to diagnose a performance discrepancy noted by an operational pilot or for data collection.

Operational flight maneuvers can be used for evaluation of a simulator in use for its intended purpose (e.g., flying instrument approaches, shipboard interface, etc.). As such, the types of evaluations performed on pilots can be used in providing a test sequence and format for the simulator validation. Examples of typical pilot evaluations (also known as examinations or check rides) include training syllabus flights, annual pilot proficiency evaluations (normal procedures and emergency training), tactical checks (tactical or special procedures), and instrument checks (pertaining to instrument flight rules; IFR). Operational flight procedures can be augmented with the Cooper-Harper handling qualities scale.

The POH typically contains various data, charts, and tables that can be used for validation testing. Individual datum and data found in tables typically includes airframe limitations (e.g., aerodynamic limitations such as airspeed, acceleration, altitude, and gross weight limits), best angle of climb airspeed $V_{X}$, best rate of climb airspeed $V_{Y}$, stall speeds $V_{S}$ at differing configurations, and center of gravity (c.g.) limitations. Data found in charts is typically performance oriented and includes takeoff, climb, range, endurance, descent, landing, mission planning (e.g., turn rate versus airspeed, turn radius versus airspeed, etc.), and emergency operation (e.g., glide). Simulator flight test data can then be collected in these areas and compared to the actual text datum, table data, or chart data. Acceptable results could be considered to be within given $\mathrm{POH}$ tolerances, chart resolution, FAA Level D simulator equivalent values, or the ICAO default of 20 percent [6].

With their typically proprietary nature and the logistical challenges posed by obtaining numerous individual aircraft maintenance test flight procedures (if they even exist) or FAA Level D time-history data, the relative availability of aircraft POHs, the increased rigor over the other listed test methodologies, and standardization and repeatability it provides, the decision was made to perform this study using test procedures from the field of experimental aircraft flight test.

\section{Reporting Considerations}

After selection of an appropriate flight model and determination of validation criteria, the test results must be documented. Detailed results reporting are described by the U.S. Naval Test Pilot School [16], the FAA [4], and the National Test Pilot School [14]. In addition, the results can be documented following the format of an aircraft's $\mathrm{POH}$. The formats in all of these references provide a valuable, detailed listing of validation results, but at the cost of lengthy documentation. For occasions where the recipient of the validation results is primarily interested in a concise summary without extensive data or procedure reporting, or where documentation preparation time is limited, a short reporting format is proposed here (Annex A). This format provides both a quick reference for the reader as well as a process to conserve authoring time.

\section{CASE STUDY FLIGHT SIMULATOR AND AIRCRAFT}

For the purposes of this study, a blade element theorybased flight simulator was chosen, with an open source aircraft model. The aircraft used here is the U.S. Navy Beechcraft T34C Turbo Mentor. The T-34C is a single-engine turbine, tandem-seat, aerobatic military training aircraft meeting the FAA definitions of both a complex airplane and of a highperformance airplane (the FAA defines a complex airplane as one that has a retractable landing gear, flaps, and controllable propeller and a high-performance aircraft as one with an engine of more than 200 horsepower). The T-34C is primarily operated at the Navy's flight schools for initial flight instruction. This airplane was selected based on ready access to an unusually detailed military flight manual, single engine simplicity (eliminating the need to test for airborne minimum control airspeed $V_{M C A}$ and other single-engine related airspeeds and rates), the fact it is no longer in production (both allowing for testing of the terminal version of the aircraft and eliminating any perception of manufacturer leaning by the Simulation Engineering Test Pilot), the model's creation by an individual hobbyist (again, preventing potential perception issues that may be associated with a corporate product), and its interesting categorization as both a complex and as a highperformance airplane, as well as due to the project Simulation Engineering Test Pilot's familiarization with and prior qualification in the actual aircraft.

The simulation environment used included a Gateway computer with an Intel T2400 CPU running at $1.83 \mathrm{GHz}$ and having 2.0 GB RAM. The operating system was Microsoft Windows XP Professional, while the peripherals included $\mathrm{CH}$ Products Fighterstick USB, CH Products Pro Throttle USB, and $\mathrm{CH}$ Products Pro Pedals USB. Data acquisition was performed automatically using a feature in the flight simulation that ports selected data (e.g., airspeed, gravity $(G)$ force, and weight) at a desired sampling rate to a text file. The selected atmosphere was clear, no wind, and visibility unlimited with temperature and pressure as described by a standard day. Unless otherwise noted, the takeoff weight or the test start weight (if the test was initiated in flight) was set to the maximum gross weight of 4400 pounds and the only special software settings were both "overspeed" and "overstress" being set in order to provide an indication of attainment of speed (V) and load factor $(\mathrm{N})$ limits.

\section{VALIDATION TESTS AND TOLERANCES}

Once the decision was made to use test procedures from the field of experimental aircraft flight test, a determination had to be made as to which individual tests would be performed, to what level data would be collected, and what performance tolerances would be used. These decisions would be based on the balance desired between being thorough in testing and in 
the desire to minimize time-consuming efforts that may result in little real qualitative or quantitative benefit or insight.

The numerous tests available in aircraft certification can be generalized into two categories: performance and handling qualities. Since the models used in the final version of the simulation tool would make use of computer pilots - and especially due to the fact that the aircraft model would not be used in the training of pilots - desirable handling qualities would not play a significant role in the aircraft model's realism. This is because the computer pilot would essentially function as a control system with some flying rules and heuristics added. As such, the computer pilot could be tuned to compensate for any undesirable or unrealistic flying qualities, either through the use of different gains, time delays, or rates in the computer pilot model or through the use of a separate flight control model (essentially a second computer pilot model to, for example, provide yaw damping so the computer pilot model does not need to). This insight allows for reducing test planning, conduct, and analysis almost in half through the elimination of all handling qualities tests.

The level of testing performed has a dramatic effect on the time required to complete the validation. Certification testing [13] includes data collection at many test points (e.g., varying weight, c.g., airspeed, etc.) and test point combinations for each test, as well as extensive data reduction (e.g., to compensate for aircraft weight changes, an imperfect atmosphere, etc.). Thorough simulation validation testing can be performed with significantly less effort than is required in a full aircraft certification program and without compromising rigor through the use of limited testing; e.g., using typical weights and c.g.s where able and appropriate. This is also consistent with ICAO [6] and FAA [2] simulator qualification tests, which are not conducted throughout the operating envelope of the aircraft. Specifically, tests are not typically repeated at, for example, various speeds, altitudes, and c.g.s (though there is nothing that prevents this; these types of tests are commonly referred to as "spot checks").

Quantifying tolerances poses a particular challenge due to the range of types (percentage of desired value, plus or minus a fixed value, or qualitative) and values (e.g., per AC 120-40B quantitative percentages include $1,5,10,20,25$, or 30 percent depending on the test) used. While many validation metrics can be gleaned from ICAO [6] and the FAA [2], when these are lacking these regulatory organizations prescribe the use of "engineering judgment." Also, since these tolerances vary, when not specified, ICAO uses 20 percent. From the area of gauge repeatability and reproducibility $(R \& R$; gauge $R \& R$ is a statistical tool that measures the amount of variation in the measurement system arising from the measurement device and the people taking the measurement) analysis, the selected acceptability criteria [12] are provided as follows:

- $\leq 10$ percent error, system is acceptable,

- $>10$ percent to $\leq 30$ percent error, system may be acceptable, and

- $\quad>30$ percent error, system needs improvement.

\section{FLIGHT TEST PROCEDURES AND RESULTS}

Performance experimental test flight procedures as described by the FAA [3] and Askue [1] were selected for validating the flight simulator and its aircraft model for use as a component in an airspace simulation tool.

\section{High-Speed Taxi}

While this flight regime is not required when the aircraft model is used as part of an en route simulation (as is the case here), it was conducted for consistency (i.e., this is a typical part of a flight test program) and for evaluation/confirmation of aircraft airspeeds and characteristics at these airspeeds.

Since the flight would be performed at an average test weight of about 3650 pounds, the stall speed $V_{S}$ was selected to be 68 knots indicated airspeed (KIAS) (clean) and 52 KIAS (gear down, full flaps) based on interpolating the figure 11-2 data as given by the U.S. Navy [15]. From this, the target liftoff speed was calculated to be $1.3 V_{S}=88.4$ KIAS (clean; rounded up to $90 \mathrm{KIAS}$ ). Also, flight test climb-out/envelope starting point speed was calculated using

$$
V_{O}=1.4 V_{S}
$$

giving $V_{O}=95.2$ (target of 95) KIAS.

High-speed taxi procedures included: repeated taxis (test for roll reversal up to just below $V_{S}$ using 60 and 70 KIAS), partial-power land backs (attain $1.3 V_{S}$, throttle to idle, take off, check roll reversal, land), and full-power land backs (attain $1.3 V_{S}$, take off, check roll reversal, throttle to idle, land).

Qualitative results include the following. During the highspeed taxi it was noted that no rolling or aircraft rocking was observed while the aircraft was still in contact with the ground; this is most likely due to a limitation of the flight simulator. No adverse yaw was observed at any of the airspeeds. During the land back, no adverse yaw was observed; effectiveness and direction of ailerons was as expected. During the full-power land back, again no adverse yaw was observed. Power-induced trim changes were observed with control possible without excessive control inputs.

The lack of aircraft rolling/rocking while in contact with the ground during high-speed taxi is not considered a limitation (due to the intended use of the model). The lack of adverse yaw is discussed further in the First Flight section.

\section{First Flight}

As with the high-speed taxi tests, this flight regime is also not required. From the previous test's calculations, the target values used for the First Flight tests included: $V_{S}=52$ KIAS (gear down, full flaps), $V_{S}=68 \mathrm{KIAS}$ (clean), $1.3 V_{S}=90$ KIAS, $V_{O}=95 \mathrm{KIAS}$, and test weight of 3650 pounds.

Procedures consisted of: maneuvering climb to test altitude, maneuvering flight characteristics and stalls (flaps up, gear up), maneuvering flight characteristics and stalls (full flaps, landing gear down in order to match stall data in $\mathrm{POH}$, though the manual indicates the effect of landing gear position is negligible on stall characteristics), accelerate to $V_{O}$ and 
descend to 800' above ground level (AGL) in the pattern, landing pattern to missed approach, and landing pattern to touchdown (see Askue [1] for further details and test points).

With the exception of a V-N plot of the first flight (figure 1), no data reduction was performed (for a given weight and configuration, an aircraft always stalls at the same indicated airspeed even though the true airspeed may be higher or lower; since approach speeds are based on a measure above stall speed, KIAS is used here as well).

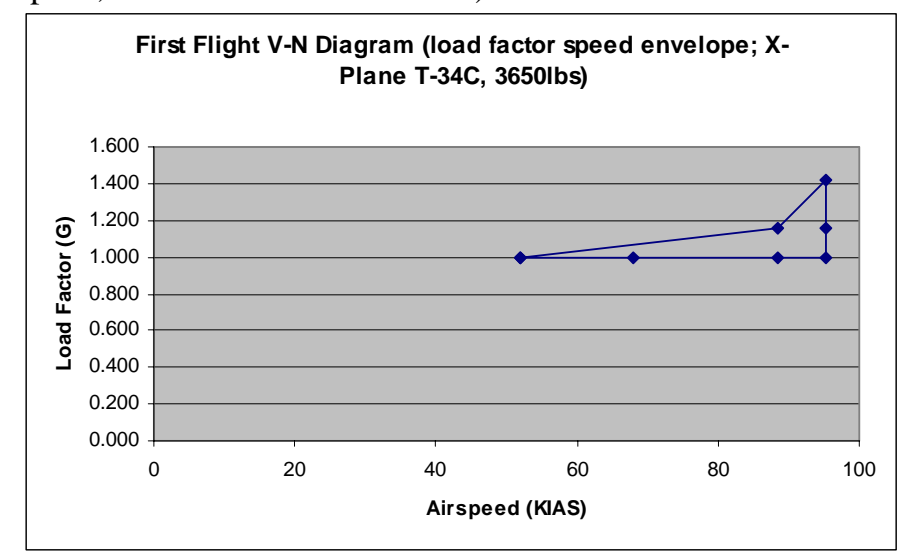

Figure 1. First flight V-N diagram.

Qualitative results are as follows. During maneuvering climb to test altitude, no adverse yaw was observed at any of the airspeeds or at any of the angles of bank (AOB); i.e., the ball was consistently centered. This is most likely attributable to a limitation of the simulator since the actual T-34C requires pedal inputs during turns. During maneuvering flight characteristics and stalls (flaps up, gear up), controls were correctly at or about mid travel and only gentle roll inputs were required for entering turns. No yaw inputs were observed to be required (see previous comments). Only minor longitudinal inputs were required to maintain altitude. No strong pitching tendencies. No strong tendencies to roll into turn. Aft stick required for deceleration to $1.3 V_{S}$; characteristics were similar to those at $V_{O}$. Stalls were conducted using the procedure in the $\mathrm{POH}$. Approximately $20^{\circ}$ nose high allowed for a poweroff stall approached at approximately one knot per second. No aerodynamic stall warning (concurs with $\mathrm{POH}$ ). No airframe buffet at the stall break (POH describes airframe buffet at the break). Clean stall speeds were typically at 68 KIAS (in agreement with $\mathrm{POH}$-determined/interpolated speed of 68 KIAS). Rolling tendency was present and controllable (in agreement with $\mathrm{POH}$ ). In maneuvering flight characteristics and stalls (full flaps/landing gear down) comments are the same as found in maneuvering flight characteristics and stalls (flaps up/gear up) except for stalls. Stalls were again conducted using the procedure in the $\mathrm{POH}$. Approximately $10^{\circ}$ nose high allowed for a power-off stall to be approached at approximately one knot per second. No aerodynamic stall warning (concurs with manual). No airframe buffet at the stall break (POH describes airframe buffet at the break). Dirty stall speeds (leftmost point in figure 1) were typically 51 KIAS (1.9 percent lower than the POH-determined/interpolated speed of 52 KIAS). Rolling tendency was present and controllable (in agreement with $\mathrm{POH}$ ). During landing pattern to missed approach no adverse characteristics noted or unusual control inputs required. In the landing pattern to touchdown no adverse characteristics noted or unusual control inputs required.

In conclusion, the calculated climbout speed is bounded by the normal operational climbout speed and the best angle of climb airspeed, which is to be expected. These results are uniquely due to the nature of the calculations and are independent of the flight model; however details of the flight model can be seen in subsequent tests determining the best rate of climb and best angle of climb airspeeds. The calculated pattern/waveoff airspeed was within 4.8 percent of the $\mathrm{POH}$, while the calculated final approach speed was within four percent of both $\mathrm{POH}$ speeds. Dirty and clean stall speeds are very accurate. Also, the lack of airframe buffet at the stall break may be indicative of blade element theory limitations in nonlinear regimes; the simulated aircraft's stall is significantly less noticeable than in the actual aircraft. The lack of aircraft yaw during turns is a significant limitation in the model. In its intended use here (i.e., airspace modeling and under pilot control), this may not be of concern since the model seems to perform what the pilot would be expected to perform; that is, keep the aircraft in balanced flight. If this model were to be used in, for example flight training, the ramifications of this limitation would need to be more seriously considered.

\section{Envelope Expansion (V-N Diagram)}

An airplane's envelope is defined by a plot of the load factor in Gs versus airspeed and is referred to as the V-N diagram. The envelope is the area within which the airplane is structurally sound and free of flutter for a given weight, altitude, and configuration.

The curved vertical line bordering the left side of the envelope (linearized in figure 2) is the accelerated stall line and depicts the largest amount of lift the wing will develop at a given speed without stalling. It starts on the left at $V_{S}$ and one $G$ and moves right and up, until the maneuvering speed $V_{A}$ at the positive load limit factor $\mathrm{N}+$ according to

$$
\mathrm{N}=\left(\mathrm{KTAS} / V_{S}\right)^{2} \text {. }
$$

Exceeding this curve will result in a stall.

The top of the envelope is typically a straight, horizontal line described by $\mathrm{N}+. \mathrm{N}+$ is determined by the structural capability of the wing and tail. It should be $2.5 \mathrm{G}$ for transport category aircraft, $3.8 \mathrm{G}$ for normal category aircraft, $4.4 \mathrm{G}$ for utility, and $6.0 \mathrm{G}$ for aerobatic category aircraft. If the limit load is exceeded, some structural damage may occur in the form of a permanent deformation due to a single application of a high load (static failure) or fatigue damage due to repeated applications of load (fatigue failure). One-and-one-half the limit load is defined as the ultimate load (3.75, 5.7, 6.6, and 9.0 $\mathrm{G}$ respectively). If the ultimate load is exceeded, the aircraft 
will suffer static failure and the simulated aircraft should have some method of recognizing this.

The rightmost vertical border of the envelope (generally a straight, vertical line) is at the never exceed airspeed $V_{N E}$ (redline airspeed beyond which the aircraft must not be flown). It is defined as 90 percent of the highest speed demonstrated by test and should be about 15 percent greater than the cruise airspeed $V_{C}$. Speeds past $1.1 V_{N E}$ will lead to any one of four aeroelastic effects. These include aileron reversal, wing divergence, wing flutter, or shock wave formation (at the critical mach number $M_{\text {crit }}$ the airflow velocity is just supersonic over the aircraft while it is still subsonic in the free airstream causing a buffet or shaking that can damage the airframe and cause the control surfaces to become ineffective).

While V-N diagrams are not usually found in POHs, $V_{A}$, $V_{S}$, and $V_{N E}$ are, and $\mathrm{N}+$ and the ultimate load are known from the aircraft's category. T-34C POH data can be seen in figure 2 .

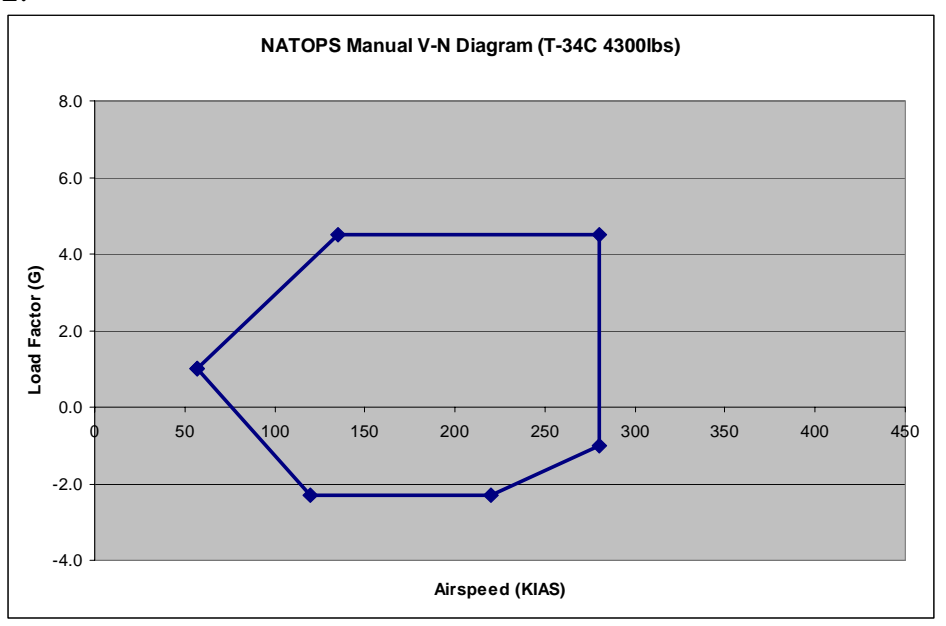

Figure 2. Linearized NATOPS manual V-N diagram.

For a simulator, V-N diagram data can be used to confirm that the aircraft can attain all points in the plot (e.g., aircraft can be flown up to $1.1 V_{N E}$ ) and to determine degradation or failures (if any) that occur outside of the envelope (e.g., aircraft stalls outside of, or on, the dynamic stall curve), their appropriateness, and how they are manifested (with the understanding that speeds past $1.1 V_{N E}$ should not be expected to show any one of four aeroelastic effects since the mechanical structure of the aircraft is most likely not modeled in the software simulation).

Here, tests were performed at one weight (a heavy weight was used since this is used in the POH V-N), one c.g. (typical c.g.; i.e., mid-c.g.), and one altitude. This is similar to FAA and ICAO simulator testing where only typical aircraft values are used. Since a minimum of 5000' AGL would normally be used for the lowest envelope expansion data collection, the tests were performed at 5000' mean sea level (MSL) collecting KIAS. POH data is given at 4300 pounds.

Other numerical values included (clean) maneuvering speed $V_{A}=156.98 \cong 157$ KIAS as calculated from

$$
V_{A}=V_{S} \cdot \sqrt{N+}
$$

and

$$
\mathrm{N}=\left(\frac{V}{V_{S}}\right)^{2}
$$

(using clean $V_{S}=74$ per the POH). Dirty stall speed of $V_{S}=56$ from the POH gives $V_{A}=118.79 \cong 119$ KIAS. (Note that $V_{A}=$ 135 KIAS per the POH.) Therefore, $1.1 V_{A}=172.68 \cong 173$ KIAS (clean; note that since this speed is in the middle of $\mathrm{POH}$ $\mathrm{V}-\mathrm{N}$ diagram, it is also used for other $\mathrm{N}$ tests) and $1.1 V_{A}=$ $130.67 \cong 131$ KIAS (dirty). Using the heavier weight stall speeds only, a climb-out speed/envelope starting point speed of $V_{O}=1.4 V_{S}=103.6 \cong 104$ KIAS (clean) was used. Other values used for the Envelope Expansion tests included: lift-off speed $1.3 V_{S}=96 \mathrm{KIAS}, V_{N E}=280 \mathrm{KIAS}(\mathrm{POH}), 1.1 V_{N E}=308 \mathrm{KIAS}$ (calculated using $\mathrm{POH}$ data), $\mathrm{N}+=4.5 \mathrm{G}(\mathrm{POH})$, and $1.5 \mathrm{~N}+=$ $6.75 \mathrm{G}$ (ultimate load calculated using POH data).

Procedures included: attain test altitude and $V_{O}$ test points followed by over-one-G test points (see Askue [1] for further details). $\mathrm{N}+$ was achieved using $\mathrm{AOB}$ up to $2 \mathrm{G}\left(60^{\circ} \mathrm{AOB}\right)$, then by using a symmetrical pull-up for values over $2 \mathrm{G}$. Negative Gs were not tested.

Data reduction was required for these tests. The test aircraft weight varied from 4357 to 4040 pounds; given test $\left(W_{\text {test }}\right)$ and standard $\left(W_{\text {std }}\right)$ weights and the test load $\left(\mathrm{N}_{\text {test }}\right)$, the corrected loads were calculated using [5]

$$
\mathrm{N}=\mathrm{N}_{\text {test }}\left(\frac{W_{\text {test }}}{W_{\text {std }}}\right) \text {. }
$$

Given V and N, the expected loads were calculated using eq. (4). Flight test-collected airspeeds were plotted versus corrected loads for the simulated aircraft's expanded envelope V-N diagram (figure 3).

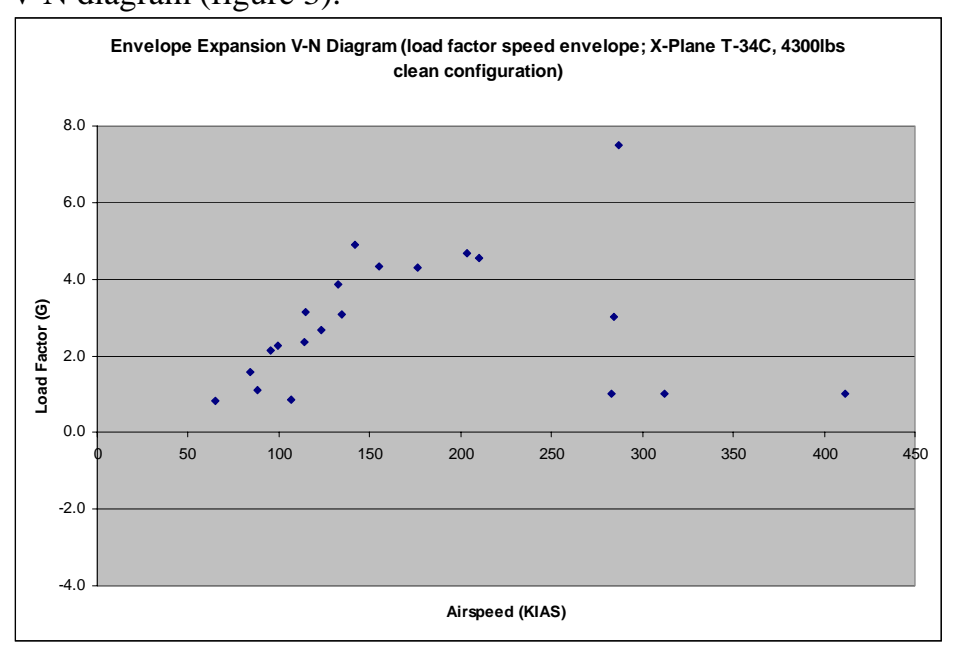

Figure 3. Test results V-N plot.

Test results were as follows. At test altitude and $V_{O}$ test points, stalls at $V_{S}$ (clean) demonstrated $V_{S}$ of 65 KIAS at $0.8 \mathrm{G}$ (per Envelope Expansion) versus 74 KIAS at $1.0 \mathrm{G}$ (per POH). 
$V_{N E}$ tests provided $V_{N E}$ of 283 KIAS at $1.0 \mathrm{G}$ (per Envelope Expansion) versus $280 \mathrm{KIAS}$ at $1.0 \mathrm{G}$ (per $\mathrm{POH}$ ); the speed was attainable with no failure or performance degradation. $1.1 V_{N E}$ test point showed $1.1 V_{N E}$ of 312 KIAS at $1.0 \mathrm{G}$ (per Envelope Expansion) versus 308 KIAS at $1.0 \mathrm{G}$ (per calculation); this speed was attainable with no failure or performance degradation. The $\mathrm{V} \geq V_{N E}$ test point indicated 411 KIAS attained (and with no failure), which is well above the calculated $1.1 V_{N E}$ of 308 KIAS.

For the over-one-G test points, $V_{N E}$ at $\mathrm{N}+$ demonstrated that the speed and load were attainable. $V_{N E}$ at $\geq \mathrm{N}+$ showed $7.5 \mathrm{G}$ at $V_{N E}$ attained before failure (an 11.1 percent difference based on the $6.75 \mathrm{G}$ calculated ultimate load per the $4.5 \mathrm{G} \mathrm{POH}$ maximum; note FAA-certified aerobatic aircraft are stressed to an ultimate load of $9 \mathrm{G}$ ). $1.1 V_{A}$ at $2 \mathrm{G}$ showed that an average AOB of 60.9 degrees over 13 seconds returned an average $G$ load of $1.97 \mathrm{G}$. $1.1 V_{A}$ at $\mathrm{N}+$ showed the load to be attainable and with no accelerated-stall characteristics demonstrated, providing a $V_{A}$ of 142 KIAS at $4.9 \mathrm{G}$ (per Envelope Expansion) versus 135 KIAS at $4.5 \mathrm{G}$ (per $\mathrm{POH}$; 5.2 percent difference) and 157 KIAS at $4.5 \mathrm{G}$ (per calculation; -9.6 percent difference). At $V_{S} \leq \mathrm{V} \leq V_{A}$ to $\mathrm{N}+$ accelerated stalls observed at various $\mathrm{N}$ and $\mathrm{V}$ values in both clean and dirty configurations.

In conclusion, the model's positive $\mathrm{V}-\mathrm{N}$ test values are within acceptable limits and appear to map accurately both to a typical V-N diagram shape as well as to the specific T-34C $\mathrm{POH}$ values. Test $V_{A}$ values appear to match well with $\mathrm{POH}$ value of $V_{A}=135 \mathrm{KIAS}$ at $4.5 \mathrm{G}$ (test points included 132 KIAS at $3.9 \mathrm{G}$ and $142 \mathrm{KIAS}$ at $4.9 \mathrm{G}$; figure 3). The failure of the model to respond to excessive airspeed is not seen as a failure in the model since it is realized that speeds past $1.1 V_{N E}$ would not be expected to show any one of four aeroelastic effects (the mechanical structure of the aircraft is most likely not modeled in the software simulation), and since the intended use of the model does not include flight at extreme airspeeds.

\section{Maximum Rate of Climb and Best Angle of Climb}

While there are several procedures for obtaining best rate of climb $V_{Y}$ and best angle of climb $V_{X}$ values (a detailed process is described by Kolano [8]), both can be readily obtained using a single FAA procedure [3].

Best rate of climb speed tests were performed using 3000' MSL as the base attitude. A full-throttle climb (using the flight simulation's ability to display various parameters digitally, since the T-34C cockpit model did not appear to accurately display torque) was initiated 1000 ' below the predetermined base altitude with the purpose of stabilizing at the preselected airspeed. These speeds started at 15 KIAS above the predicted best rate of climb speed and decreased in increments of 5 KIAS down to an airspeed 10 KIAS above $V_{S}$. The resulting target speeds included 115, 110, 105, 100, 95, 90, and 85 KIAS. As the aircraft climbed through the base altitude, a one-minute time check was initiated, at the end of which the altitude was recorded. The aircraft was then descended and the process was repeated at the next speed. The best angle of climb speed tests make use of the same data.

Data reduction consisted of converting the times and altitudes to rates of climb and plotting these versus airspeed using spreadsheet software. The software was then used to fit a second-order polynomial curve to the data. The airspeed that showed the greatest gain in altitude is the aircraft's best rate of climb airspeed $V_{Y}$. Best angle of climb speed is then found by constructing a tangent line from the origin outward to a point on the rate of climb airspeed curve. At this intersection, a line is constructed straight down to the airspeed leg of the chart. The airspeed that the line intersects is the best angle of climb airspeed $V_{X}$.

Test results included a best rate of climb airspeed of $V_{Y}=$ 101 KIAS (100 per the $\mathrm{POH}$ ) and a best angle of climb airspeed of $V_{X}=71$ KIAS (75 per the $\mathrm{POH}$ ) giving differences of 1.0 and -5.3 percent respectively (figure 4 ).

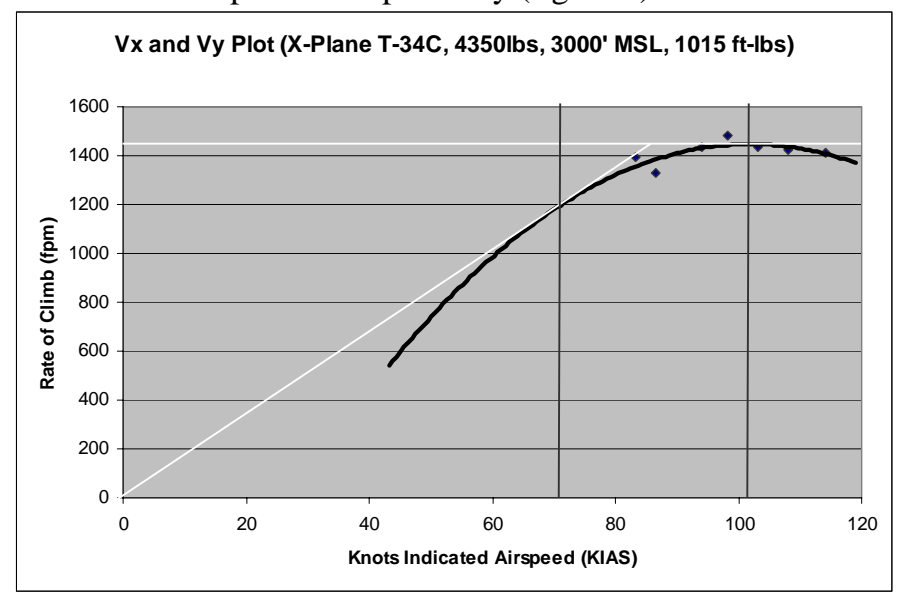

Figure 4. Measured airplane performance curves.

\section{Other Flight Tests}

Additional flight tests were performed, not all of which are documented in this paper (e.g., the maximum cruise-power speed test as detailed in Annex A; this airspeed was obtained by averaging over a period of just under four minutes) or in Annex A (e.g., stall angle of attack). In addition, normal IFR operations were rated using the Cooper-Harper handling qualities scale while flying an instrument landing system (ILS) approach to minimums. These tests were performed in the interest of better understanding the model and for the purpose of refining the contents of the reporting format seen in Annex A.

\section{VALIDATION RESULTS AND REPORTING FORMAT}

Overall, the results were promising, with a high correlation between the test data collected and the values provided in the POH. Most of the errors fell between -5.3 and +3.6 percent. The one Conditionally Acceptable point (a higher than expected maximum cruise-power airspeed value, ultimately resulting in an overall validation rating of Conditionally Acceptable; i.e., the worst-performing test delta determines the 
simulator's qualitative assessment) was found at 14.1 percent. However, the average overall performance (calculated using the average of the absolute values of the test deltas) of the flight simulator using the $\mathrm{T}-34 \mathrm{C}$ aircraft model was rated as Acceptable at almost 96 on a scale of 100.

The reporting format shown in Annex A provides an interested party with a short summary of the flight simulator's performance using a given aircraft model and test equipment. The title contains the name of the simulator and model evaluated and is followed by a summary of the results [9] using a 4-tuple to provide information on the type of testing done, while a triplet provides information on the person conducting/responsible for the testing. Two tables follow, one which describes the selection of the 7-tuple values, and one which provides test descriptions and references, test data, reference (e.g., $\mathrm{POH}$ ) data, percentage deviations, and further details on the individual tests performed. (Note that not all of the tests are used in the qualification consideration; the tests listed further down in the table provide amplifying information but do not affect the simulator's/model's overall score.) Additional information includes a listing of the simulation environment and the author of the aircraft model.

\section{SUMMARY}

In this paper, a process based in aircraft certification flight test was proposed for validating flight simulators for use in unregulated applications (e.g., simulators not requiring FAA qualification for use) and demonstrated using a commonly available flight simulator and an open-source aircraft model. The process demonstrated the objective, rigorous, and qualitative nature of the evaluation methodology. A compact, results reporting format was also developed and demonstrated.

\section{ACKNOWLEDGMENTS}

This paper is based on work supported under RITA/VNTSC \#FA8G ED972. Any opinions, findings, and conclusions or recommendations expressed in this paper are those of the author.

\section{REFERENCES}

[1] Askue, V., Flight Testing Homebuilt Aircraft, Iowa State University Press, Ames, IA, 1992.

[2] Federal Aviation Administration, Airplane Simulator Qualification, Advisory Circular 120-40B, U.S. Government Printing Office, Washington, D.C., 1991.

[3] Federal Aviation Administration, Amateur-Built Aircraft and Ultralight Flight Testing Handbook, Advisory Circular 90-89A, U.S. Government Printing Office, Washington, D.C. , 1995.

[4] Federal Aviation Administration, Flight Test Guide for Certification of Transport Category Airplanes, Advisory Circular 25-7A, U.S. Government Printing Office, Washington, D.C., 1998.

[5] Gardner, L., Painter, D., and Weaver, H. (eds), Society of Flight Test Engineers Reference Handbook, Second
Edition, Society of Flight Test Engineers, Lancaster, CA, 2007.

[6] International Civil Aviation Organization, Manual of Criteria for the Qualification of Flight Simulators, Document 9625, Second Edition, International Civil Aviation Organization, Montréal, Canada, 2003.

[7] Kimball, D., Hurtig, L. A., and Galloway, R. T., "Flight Simulation Model Development and Validation for The JPATS Ground Based Training System," Proceedings of the American Institute of Aeronautics and Astronautics Modeling and Technologies Conference and Exhibit, AIAA-2002-4598, Monterey, CA, 2002.

[8] Kolano, E., "How to Test Your Airplane's Best Climb Rate and $\mathrm{V}_{\mathrm{y}}$," Flight Training, Vol. 10, No. 11, pp. 20-27, 1998.

[9] McGovern, S. M., "Categories for Classification of Aircraft Flight Model Validation,” Proceedings of the IEEE/AIAA $26^{\text {th }}$ Digital Avionics Systems Conference, Dallas, Texas, October 21-25, CD-ROM, 2007.

[10] McGovern, S. M. and Cohen, S. B., "Survey of Contemporary Aircraft Flight Dynamics Models for Use in Airspace Simulation,” Proceedings of the 2007 SPIE Defense and Security Symposium, International Conference on Modeling and Simulation for Military Operations II, Orlando, Florida, April 10-12, Vol. 6564, CD-ROM, 2007.

[11] McGovern, S. M., Cohen, S. B., Truong, M., and Fairley, G., "Kinematics-Based Model for Stochastic Simulation of Aircraft Operating in the National Airspace System," Proceedings of the IEEE/AIAA $26^{\text {th }}$ Digital Avionics Systems Conference, Dallas, Texas, October 21-25, CDROM, 2007.

[12] Mehta, M., “Ask the Experts; Gage R\&R,” Industrial Engineer, Vol. 39, No. 6, Norcross, GA, pp. 54-55, 2007.

[13] National Test Pilot School, Introduction to Performance and Flying Qualities Flight Testing, Second Edition, National Test Pilot School, Mojave, CA, 1995.

[14] National Test Pilot School, Technical Reports Manual, Revision H, National Test Pilot School, Mojave, CA, 2003.

[15] U.S. Navy, NATOPS Flight Manual Navy Model T-34C Aircraft, Change 1, Chief of Naval Operations, Washington, D.C., 1984.

[16] U.S. Naval Test Pilot School, Report Writing Handbook, Change 3, U.S. Naval Test Pilot School, Patuxent River, MD, 1997.

[17] Wentzel, K. C., “An Informative Guide to Qualification of Flight Simulators for Commercial Aircraft,” Proceedings of the American Institute of Aeronautics and Astronautics Flight Simulation Technologies Conference, AIAA-19953395, Baltimore, MD, pp. 63-76, 1995. 
ANNEX A

FLIGHT SIMULATOR VALIDATION REPORTING FORMAT EXAMPLE

\author{
U.S. Navy Beechcraft T-34C Turbo Mentor \\ S|CERT|OBJ|C: A|A|A
}

30 May 2008

Vali dati On Notati On Detai ls $(\alpha|\beta| \gamma|\delta: \varepsilon| \zeta \mid \eta)$

\begin{tabular}{|c|c|c|}
\hline$\alpha$ & Intended application for model & Airspace simulation \\
\hline$\beta$ & Validation test description & $\begin{array}{l}\text { Experimental flight test - performance only; no handling qualities tests performed (other } \\
\text { than a Cooper-Harper rated precision approach) due to the use of a computer pilot for } \\
\text { implementation of stability in the final application, and due to use not including pilot training }\end{array}$ \\
\hline$\gamma$ & Tester's affiliation & U.S. DOT Volpe National Transportation Systems Center \\
\hline$\delta$ & Test results & $\begin{array}{l}\text { Judged to be Conditionally Acceptable for intended use in airspace simulation (i.e., aircraft } \\
\text { operating in normal flight regimes and profiles) using gauge R\&R criteria. Overall } \\
\text { performance Acceptable at an average of } 95.8 \text { (on a scale of 100) }\end{array}$ \\
\hline$\varepsilon$ & $\begin{array}{l}\text { Simulation Engineering Test } \\
\text { Pilot aviation licensing }\end{array}$ & $\begin{array}{l}\text { FAA Airline Transport Pilot certificate (Airplane Single Engine Land and Instrument Airplane } \\
\text { privileges; also, Complex Aircraft and High Performance Aircraft experience via T-34C } \\
\text { aircraft qualification) }\end{array}$ \\
\hline$\zeta$ & $\begin{array}{l}\text { Simulation Engineering Test } \\
\text { Pilot flight test qualifications }\end{array}$ & $\begin{array}{l}\text { National Test Pilot School, Introduction to Fixed Wing Flight Testing short course; U.S. } \\
\text { Army Maintenance Test Pilot and U.S. Navy Functional Check Pilot designations }\end{array}$ \\
\hline$\eta$ & $\begin{array}{l}\text { Simulation Engineering Test } \\
\text { Pilot academic degree }\end{array}$ & $\begin{array}{l}\text { Ph.D. Industrial Engineering, Northeastern University, Boston, MA, U.S.A. (ABET } \\
\text { accredited - Industrial Engineering, 1939; Next General Review 2007-08) }\end{array}$ \\
\hline
\end{tabular}

Representative Test Results and Origi nal Data

\begin{tabular}{|c|c|c|c|c|}
\hline $\begin{array}{l}\text { Test Parameter (Units, Additional Parameter } \\
\text { Information, Reference Location }^{1} \text { ) }\end{array}$ & $\begin{array}{c}\text { Test } \\
\text { Result }\end{array}$ & $\begin{array}{l}\text { Reference } \\
\text { Datum }\end{array}$ & \% Delta & $\begin{array}{c}\text { Relevant Test } \\
\text { Parameters/Notes }\end{array}$ \\
\hline$V_{S}(\mathrm{KIAS}$, stall speed - landing configuration, Fig 24-13) & 51 & 52 & $1.9 \%$ & $3650 \mathrm{lbs}$ \\
\hline$V_{S}(\mathrm{KIAS}$, stall speed - clean, Fig 24-13) & 68 & 74 & $0.0 \%$ & $3650 \mathrm{lbs}$ \\
\hline Maximum cruise-power speed (KIAS, N/A, Fig 27-2) & 204.2 & 179 & $14.1 \%$ & $\begin{array}{l}4100 \mathrm{lbs}, 4000^{\prime} \mathrm{msl}, 7^{\circ} \mathrm{C} \text {, } \\
955 \mathrm{ft}-\mathrm{lbs}\end{array}$ \\
\hline$V_{X}(\mathrm{KIAS}$, maximum angle of climb airspeed, $\S 7.10)$ & 71 & 75 & $-5.3 \%$ & $\begin{array}{l}4300 \text { lbs, } 4000 \text { ' msl, } 100 \\
\text { KIAS, } 1015 \text { ft-lbs }\end{array}$ \\
\hline$V_{Y}(\mathrm{KIAS}$, maximum rate of climb airspeed, § 7.10) & 101 & 100 & $1.0 \%$ & $\begin{array}{l}4300 \text { lbs, } 4000 \text { ' msl, } 100 \\
\text { KIAS, } 1015 \text { ft-lbs }\end{array}$ \\
\hline Maximum rate of climb at $V_{Y}(\mathrm{fpm}, \mathrm{N} / \mathrm{A}$, Fig 26-1) & 1450 & 1400 & $3.6 \%$ & $\begin{array}{l}4300 \text { lbs, } 4000 \text { ' msl, } 100 \\
\text { KIAS, } 1015 \text { ft-lbs }\end{array}$ \\
\hline$V_{A}$ (interpolated KIAS, maneuvering airspeed, § 11.6) & 130.4 & 135 & $-3.4 \%$ & $4.5 \mathrm{G}, 4300 \mathrm{lbs}$ \\
\hline$V_{M C A}(\mathrm{KIAS}$, static minimum controllable airspeed, N/A) & $\mathrm{N} / \mathrm{A}$ & N/A & $\mathrm{N} / \mathrm{A}$ & $\mathrm{N} / \mathrm{A}$ \\
\hline $\begin{array}{l}\text { Overall performance score (100 max): } \geq 90 \text { acceptable, } \\
<90 \text { to } \geq 70 \text { conditionally acceptable, }<70 \text { unacceptable }\end{array}$ & & & 95.8 & \\
\hline $\begin{array}{l}1.1 V_{N E}(\mathrm{KIAS}, 1.1 \text { times never exceed airspeed; } \\
\text { aeroelastic effects - here: excessive horizontal stabilizer } \\
\text { loads at }>280 \mathrm{KIAS}, \S 4.6 .1 \text { ) }\end{array}$ & attained & 311.1 & $0 \%$ & $\begin{array}{l}\text { Note: } 411 \text { KIAS attained } \\
\text { with no failure of any } \\
\text { type indicated }\end{array}$ \\
\hline $\begin{array}{l}\text { Ultimate load (G, } 1.5 \text { times limit load of } 4.5 \text { per Navy } \\
\text { manual or } 6.0 \text { for FAA aerobatic category, Fig } 4-3 \text { ) }\end{array}$ & 7.5 & $\begin{array}{c}6.75 \\
(9.0 \mathrm{FAA})\end{array}$ & $\begin{array}{c}11.1 \% \\
(-16.7 \%)\end{array}$ & $\begin{array}{l}287 \mathrm{KIAS}\left(\sim V_{N E}\right), \mathrm{GW} \\
\text { adjusted to } 4400 \mathrm{lbS}\end{array}$ \\
\hline $\begin{array}{l}\text { Cooper-Harper handling qualities evaluation (scale of } 1 \\
\text { to } 10 \text {, ILS approach, unknown) }\end{array}$ & 2 & 1,2 , or 3 & $0 \%$ & $\begin{array}{l}1 \text { to } 3 \text { defined as } \\
\text { "Satisfactory" }\end{array}$ \\
\hline
\end{tabular}

Simulation environment: Gateway with Intel T2400 CPU at $1.83 \mathrm{GHz}, 2.0 \mathrm{~GB}$ RAM, Microsoft Windows XP Professional, CH Products Fighterstick USB, CH Products Pro Throttle USB, CH Products Pro Pedals USB

Aircraft model author(s): navyaerophys model downloaded on 25 April 2007

${ }^{1}$ U.S. Navy, NATOPS Flight Manual Navy Model T-34C Aircraft, 0801-LP-258-4531, Change 1 dated 1 July 1986, Naval Air Technical Services Facility, Philadelphia, PA, 1984. 